\title{
A Study on Asymmetric Effect of Gold and Crude Oil Price Volatility
}

\author{
Cha Soon Choi \\ Associate Professor 31020 Dept. of Real Estate Studies, Namseoul University, 91 \\ Daehakro, Seonghwan-eup, Seobuk-gu, Sheonan-si, Chungnam, Seoul, Korea \\ chasoon@nsu.ac.kr
}

\begin{abstract}
In this study, we analyzed whether the volatility of gold and oil prices is asymmetric according to the type of information using GJR (1,1)-MA (1) model and EGARCH(1,1)-MA (1) model. The data used for the analysis is the daily index for gold and crude oil prices from January 2, 2015 to June 2019. Through these analysis, serveral remarkable results are found, it was found that crude oil has an asymmetric response to volatility regardless of the volatility estimation model. Gold was found to have asymmetry in variability only in the EGARCH $(1,1)$ MA (1) model. As the oil market can see asymmetric volatility in bad news rather than good news, it is necessary to supply crude oil stably when economic conditions are more favorable.
\end{abstract}

Keywords: Gold price, Oil price, Volatility, Asymmetric effect, GJR model

\section{Introduction}

Volatility in the stock market reacts strongly and sometimes weakly to the flow of information that frequently arrives. In general, the more important the information on the stock price, the greater the volatility. Volatility refers to the risk in the stock market and is, therefore, an important variable in determining the relationship between risk and stock returns. Just as volatility plays an important role in the flow of information in the stock market, the same principles can be applied in the gold and crude oil markets. In other words, whenever there are bad news such as natural disasters such as war or earthquake, economic recession, and political and social instability, or good news such as booming economy, development of advanced technology, and international patent acquisition in the gold and the crude oil markets, the gold and the crude oil price fluctuates significantly. Many pieces of research have been conducted on whether the response of stock volatility is symmetrical or asymmetrical depending on whether the information affecting the stock price is bad or good. Many previous studies including that of Black (1976) suggested that the volatility of stock prices is asymmetrical, responding more sensitively to bad news than to good news. Later, Bollerslev (1986) analyzed asymmetric responses to information using various asymmetric models. However, these previous studies are mainly conducted on the stock market, and the studies on the gold and oil markets are insufficient. Therefore, this study empirically analyzes whether the volatility of gold and crude oil price is asymmetric according to the type of information reaching the gold and crude oil market using EGARCH model and GJR model.

The research on asymmetric responses in the stock market includes Black (1976), Bollerslev (1986), and Albu, Lupu, and Călin (2015). And the studies done in Korea include Gam Hyeonggyu, Shin Yongjae, and Park Hyeongjoong (2007). Black (1976) described asymmetry

Article history:

Received (April 7, 2019), Review Result (July 9, 2019), Accepted (November 12, 2019) 
volatility with the leverage effect. In other words, if a company's stock price falls, the company's asset value will drop, leading to an increase in debt and corporate volatility. [1] Bollerslev (1986) proposed a GARCH model generalized by applying past conditional variances to the ARCH model proposed by Engle in 1982. [2]Albu, Lupu, and Călin (2015) used the GARCH model to empirically analyze asymmetric responses in Eastern European stock markets under advanced macroeconomic environments. As a result, the analysis revealed that there was a negative relationship between volatility and return on financial assets. [3] Gam, Shin, and Park (2007) analyzed the effects of stock price volatility according to the type of information using the Korean stock index by the industry for 16 years from January 2, 1990 to December 31, 2005 using GJR model and EGARCH model. As a result, it was analyzed that the unexpected negative (-) returns in the stock market for construction, finance, and manufacturing increased volatility over unexpected positive (+) returns. When analyzing the period before and after the 1997 Asian Financial Crisis, this phenomenon analyzed that the bad news had a greater impact on the stock price volatility compared to the good news before the 1997 Asian Financial Crisis [4].

This study is unique in the sense that while most of the previous studies have focused on empirically analyzing the asymmetric response in the stock market, this study is the first to attempt to empirically analyze the asymmetric response following the type of information on the gold and crude oil prices. Chapter 2 describes the analysis method, Chapter 3 shows the result of the analysis, and Chapter 4 summarizes the conclusion and implications.

\section{Analysis method}

\subsection{GJR(1,1)-MA(1) model}

There are various models that can analyze asymmetric responses according to the types of information, but this study uses the widely used models - the GJR-MA model of Glosten,Jagannathan andRunkle (1993) and the EGARCH-MA model of Nelson (1991) for a brief explanation. [5][6] The best model for analyzing asymmetric responses to information is known as the GJR model. The EGARCH model can distort the estimation results by exaggerating conditional variability during estimation. However, this model was used for the analysis for comparison purposes. The addition of the moving average (MA) to the GJR model and the EGARCH model is intended to eliminate the unexpected autocorrelation of gold and oil yields. For the degree of MA, GJR (1,1)-MA (1) and EGARCH $(1,1)$-MA (1) were adopted in accordance with the parsimony principle of the model according to the AIC and SBC statistics. The GJR (1,1)-MA (1) model can be expressed as the following Equation (1).

$$
\begin{gathered}
R_{t}=\alpha_{0}+\alpha_{1} \varepsilon_{t-1}+\varepsilon_{t} \ldots \ldots \ldots \ldots \ldots \ldots \ldots \ldots \\
\quad \ldots \ldots \varepsilon_{t}=\left|\Omega_{t-1}\right| \sim N\left(0, h_{t}\right) \\
h_{t}=\gamma_{0}+\gamma_{1} h_{t-1}+\beta \varepsilon_{t-1}^{2}+\theta_{D} S_{t-1}^{-} \varepsilon_{t-1}^{2} \\
\ldots . \text { Here, } S_{t-1}^{-}= \begin{cases}1, & \varepsilon_{t-1}<0 \\
0, & \varepsilon_{t-1} \geq 0\end{cases}
\end{gathered}
$$

In Equation (1), $R_{t}$ refers to the daily returns, whereas $\Omega_{t-1}$ shows the set of all information up to t-1. $\varepsilon_{t}, \varepsilon_{t-1}$ is a new set of information at each point in time. A positive $\varepsilon_{t,}, \varepsilon_{t-1}$ means favorable information, whereas a negative number means unfavorable information. Favorable information means a rise in gold and oil price returns, and unfavorable information means a fall in gold and oil price returns. $h_{t}$ shows conditional dispersion. $S_{t-1}^{-}$is a dummy variable to show 
the asymmetry of information. When $\varepsilon_{t-1}$ is negative (-), it becomes 1 , and when $\varepsilon_{t-1}$ is positive (+), it becomes 0 . Therefore, $S_{t-1}^{-} \varepsilon_{t-1}^{2}$ shows the asymmetry in the gold and oil price volatility. If the coefficient $\theta_{D}$ is positive, it means that negative $\varepsilon_{t-1}$ (bad) of t- 1 increases the volatility of gold and oil prices in $t$ more than the positive $\varepsilon_{t-1}$ (good).

\subsection{EGARCH(1,1)-MA(1) model}

The EGARCH (1,1)- MA (1) model can be expressed as Equation (2).

$$
\begin{gathered}
R_{t}=\alpha_{0}+\alpha_{1} \varepsilon_{t-1}+\varepsilon_{t} \ldots \ldots \ldots \ldots \ldots \ldots \ldots(2) \\
\varepsilon_{t}=\left|\Omega_{t-1}\right| \sim N\left(0, h_{t}\right) \\
\sigma_{t}^{2}=\exp \left[\omega+\alpha\left|\frac{\varepsilon_{t-1}}{\sigma_{t-1}}\right|+\gamma \frac{\varepsilon_{t-1}}{\sigma_{t-1}}+\beta \log \left(\sigma_{t-1}^{2}\right)\right]
\end{gathered}
$$

The EGARCH $(1,1)$-MA (1) model is a model that relaxes the constraints on parameters. If $|\beta|<1$ in the conditional variance of Equation (2), the estimated conditional variance becomes stable. The parameter that measures the asymmetric effect is $\gamma \cdot \gamma$ 's coefficient is a negative value; it means an asymmetric response to the residual $\varepsilon_{t-1}$ of $t-1$. In other words, it means that the conditional variability responds greater to adverse information than to favorable information

\section{Analysis result}

\subsection{Time series data and stability examination}

This study took the daily index of gold and the North sea oil price announced by Federal Reserve Bank of St. Louis and used the daily rate of change. The gold price index is the closing price per 3 pm London time in dollar, and the North sea oil price index is the daily closing price per barrel in dollar. The data from January 2, 2015 to June 2019 were used, and the basic statistics of the data are shown in Table 1.

Table 1. Basic statistics on gold and crude oil price index returns

\begin{tabular}{|c|c|c|}
\hline & Gold & Crude oil \\
\hline Mean $(\times 102)$ & 0.0165 & 0.0173 \\
\hline Standard deviation $(\times 102)$ & 0.8022 & 2.2523 \\
\hline Skewness & 0.3152 & 0.2747 \\
\hline Kurtosis & 5.5462 & 4.7763 \\
\hline Jarque-Bera & 320.82 & 164.65 \\
Statistics & $(0.0000)$ & $(0.0000)$ \\
\hline
\end{tabular}

Note) () is of the significance level where the null hypothesis can be rejected.

Distortion was found to be biased in the positive (+) direction for both gold and crude oil, and kurtosis showed a sharper point than the normal distribution. The Jarque-Bera test result rejects the null hypothesis where the distribution of the volatility of oil and crude oil price is a normal distribution at the $1 \%$ significance level, therefore, the GARCH model is required based on this variance. Time series analysis, on the other hand, requires a stationary check. Thus, to examine the stationary of the variable, the augmented Dickey-Fuller (ADF) unit root test through PP unit root test was performed. [7][8] The results are as shown in Table 2, and the logarithmic time series data of each index were stable at $1 \%$ significance level. 
Table 2. Unit root test result

\begin{tabular}{|c|c|c|c|c|}
\hline \multirow{2}{*}{} & \multicolumn{2}{|c|}{ Gold } & \multicolumn{2}{c|}{ Crude Oil } \\
\cline { 2 - 5 } & Level variable & $1^{\text {st }}$ difference variable & Level variable & $1^{\text {st }}$ difference variable \\
\hline ADF(lag1) & -1.8227 & $-33.3614 * * *$ & -1.5423 & $-33.1649^{* * *}$ \\
\hline $\mathrm{PP}(1 \mathrm{ag} 1)$ & -2.0072 & $-33.3841^{* * *}$ & -1.6268 & $-33.1649^{* * *}$ \\
\hline
\end{tabular}

\subsection{Estimation by the model}

The GJR (1,1)-MA (1) model and the EGARCH (1,1)-MA (1) model were used to analyze whether the volatility of gold and crude oil price index returns on information was asymmetric. The maximum likelihood estimate was used for the parameters of each model, and the maximum likelihood estimate used the nonlinear optimization technique based on the BHHH algorithm. The results of estimating volatility by GJR (1,1)-MA (1) model are shown in Table 3. $\alpha_{1}$, the estimated coefficient of MA (1), was found to be insignificant for both gold and crude oil. The coefficient of $\theta_{\mathrm{D}}$, which represents the asymmetry of volatility, is not significant in gold but has a significant positive value at $1 \%$ in crude oil. Thus, the crude oil price index showed an asymmetric response to volatility. This means favorable information increases the crude oil price volatility more than adverse information does.

Table 3. Estimation results for GJR (1,1)-MA (1) model

\begin{tabular}{|c|c|c|}
\hline Statistics & Gold & Crude Oil \\
\hline$\alpha_{0}\left(\times 10^{2}\right)$ & $0.0129(0.559)$ & $0.0002(0.036)$ \\
\hline$\alpha_{1}$ & $0.0443(1.334)$ & $0.0217(0.699)$ \\
\hline$\gamma_{0}\left(\times 10^{2}\right)$ & $0.0000(2.643)^{* * *}$ & $0.0000(2.808)^{* * * *}$ \\
\hline$\gamma_{1}$ & $0.9610(137.594)^{* * *}$ & $0.9463(93.254)^{* * *}$ \\
\hline$\beta$ & $0.0371(5.097)^{* * *}$ & $0.0052(0.653)$ \\
\hline$\theta_{\mathrm{D}}$ & $-0.0112(-1.313)$ & $0.0721(4.928)^{* * *}$ \\
\hline Log likelihood & 3868.87 & 2785.15 \\
\hline
\end{tabular}

The results of estimating volatility by EGARCH $(1,1)$-MA (1) model are shown in Table 4. $\alpha_{1}$, the estimated coefficient of MA (1), was significant at $10 \%$ for gold, but not for crude oil. $\gamma$, which represents asymmetry of volatility, was found to have significant positive value at the $10 \%$ level for gold, and for crude oil, it had significant negative value at the $1 \%$ level. It can be seen that crude oil has an asymmetric response to adverse information rather than favorable information. This means that if bad news such as war or economic downturn occur, the oil price volatility will increase compared to when good news occur. But gold appears to be more responsive to favorable information than to adverse information.

Table 4. Estimation results for EGARCH (1,1)-MA (1) model

\begin{tabular}{|c|c|c|}
\hline Statistics & Gold & Crude oil \\
\hline$\alpha 0(\times 102)$ & $0.0132(0.565)$ & $0.0004(0.072)$ \\
\hline$\alpha 1$ & $0.0540(1.637)^{*}$ & $0.0171(0.568)$ \\
\hline$\omega$ & $-0.1538(-3.8254)^{* * *}$ & $-0.1446(-4.647)^{* * *}$ \\
\hline$\alpha$ & $0.0828(4.752)^{* * *}$ & $0.0514(3.943)^{* * *}$ \\
\hline
\end{tabular}




\begin{tabular}{|c|c|c|}
\hline$\gamma$ & $0.0145(1.771)^{*}$ & $-0.0711(-6.963)^{* * *}$ \\
\hline$\beta$ & $0.9906(280.09)^{* * *}$ & $0.9864(290.19)^{* * *}$ \\
\hline Log likelihood & 3867.42 & 2791.24 \\
\hline Note) 1. () shows the $z$ statistics. $2 . p<0.01^{* * *}, p<0.05^{* *}, p<0.1^{*}$
\end{tabular}

\section{Conclusion}

This study used the daily index of gold and the North sea oil price announced by Federal Reserve Bank of St. Louis to compare and analyze the asymmetry of impact each type of information has on each index' volatility with the GJR $(1,1)$-MA (1) model and the EGARCH $(1,1)$-MA (1) model. As a result, it was confirmed that crude oil has an asymmetric response to volatility regardless of the volatility estimation model. In the GJR (1,1)-MA (1) model, the asymmetric response of volatility could not be confirmed for gold. However, in the EGARCH $(1,1)$-MA (1) model, $\gamma$, which represents the asymmetry of variability, was found to have significant positive value at the $10 \%$ level.

The results of this study have the limitation that only the historical returns and volatility of the index are used as variables to explain the current returns and volatility. Nevertheless, the following implications can be drawn. The oil market shows asymmetric volatility in bad news rather than good news. Therefore, it is necessary to supply crude oil stably when economic conditions are more favorable. This study is meaningful in that it can be used as basic data for subsequent studies by first presenting the asymmetric volatility response of information on gold and crude oil. For the robustness of future research, the necessity for further expansion and analysis of macroeconomic data is required.

\section{Acknowledgements}

The funding for this paper was provided by Namseoul University, South Korea.

\section{References}

[1] F. Black, "Studies of stock price volatility changes," Proceedings of the 1976 Meeting of the Business and Economic Statistics Section, American Statistical Association, Washington DC, 177-181, (1976)

[2] T. Bollerslev, "Generalized Autoregressive Conditional Heteroskedasticity," Journal of Econometrics, vol.31, no.3, pp.307-327, (1986) DOI: 10.1016/0304-4076(86)90063-1

[3] L. L. Albu, R. Lupu and A. C. Călin, "Stock market asymmetric volatility and macroeconomic dynamics in Central and Eastern Europe," Procedia Economics and Finance. vol.22, pp.560-567, (2015) DOI: $10.1016 /$ S2212-5671(15)00259-2

[4] H. K. Gam, Y. J. Shin and H. J. Park, “Asymmetric Volatility of Stock Returns by Industry in Korea,” Korean Corporation Management Review, vol.14, no.1, pp.99-112, (2007)

[5] L. Glosten, R. Jagannathan and D. E. Runkle, "Relationship between the expected value and the volatility of the norminal excess return on stocks," Working Paper, Department of Finance, Columbia University, (1989)

[6] D. B. Nelson, "Conditional Heteroscedasticity in Asset Return: A New Approach," Econometrica, vol.59, pp.347-370, (1991)

[7] D. Dickey and W. A. Fuller, "Distribution of estimates for autoregressive time series with a unit root," Journal of the American Statistical Association, vol.74. pp.427-431, (1979)

[8] P. C. Phillips and P. Perron. "Testing for a Unit Root in Time Series Regression," Biometric, vol.75, pp.335346, (1988) DOI: 10.1093/biomet/75.2.335 


\section{Authors}

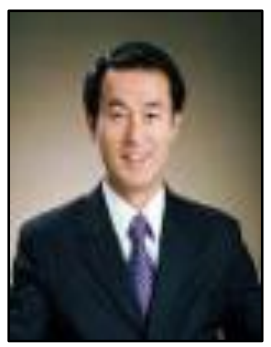

\section{Cha Soon Choi}

March 2 2009 : Associate Professor

Dept.of Real Estate Studies, Namseoul University

Editor of the International Journal of Business and Economic Research

Vice President of Korea Real Estate Academy 